\title{
Xamanismo e enteogenia ameríndia: a ayahuasca e outras "plantas de poder" em contextos indigenistas e vegetalistas amazônicos
}

Wagner Lins Lira Universidade Federal de Pernambuco

Resumo: Este ensaio tem a finalidade de refletir sobre fenômenos culturais e etnológicos condizentes aos saberes e perspectivas ameríndios acerca do uso de substâncias enteogénicas, tangencialmente, da bebida ayahuasca, cujas matrizes repousam em contextos indigenistas, desde tempos pré-colombianos. Igualmente, visamos discorrer sobre o curandeirismo vegetalista em áreas rurais e urbanas fenômeno, onde verificamos técnicas de cura e feitiçaria coadunando-se ao catolicismo e ao esoterismo europeu em modalidades alusivas à reinterpretação mítica e ritualística do consumo de "plantas de poder". Por fim, indicaremos como tais saberes são ressignificados à luz de modelos contemporâneos sul-americanos, permitindo-se ao diálogo entre médicos, psicólogos e xamãs voltados ao tratamento de sujeitos afetados por toxicomanias.

Palavras chave: Ayahuasca; Xamanismo; Vegetalismo; Terapias. 


\title{
Xamanismo y enteogenia amerindia: La ayahuasca y otras "plantas de poder" en contextos indigenistas y vegetalistas amazónicos
}

\begin{abstract}
Resumen: Este artículo tiene la finalidad de reflexionar sobre fenómenos culturales y etnológicos referentes a los saberes y perspectivas amerindios acerca del uso de sustancias enteogénicas, especialmente de la bebida ayahuasca, cuyas matrices reposan en contextos indigenistas, desde tiempos precolombinos. Igualmente, pretendemos discurrir sobre el curandirismo vegetalista en áreas rurales y urbanas fenómeno, donde verificamos técnicas de curación y brujería asociadas al catolicismo y al esoterismo europeo en modalidades referentes a la reinterpretación mítica y ritualística del consumo de "plantas de poder". Por último, indicamos cómo estos saberes son resignificados a la luz de modelos contemporáneos sudamericanos, permitiendo el diálogo entre médicos, psicólogos y chamanes dirigidos al tratamiento de sujetos afectados por toxicomanías.
\end{abstract}

Palabras clave: Ayahuasca. Chamanismo. Vegetalismo. Terapias

\section{Shamanism and amerindian entheogeny: the ayahuasca and other "power plants" in indigenist and vegetalist amazon contexts}

\begin{abstract}
This essay aims to reflect on cultural and ethnological phenomena consistent with amerindian knowledge and perspectives on the use of entheogenic substances, especially, the ayahuasca drink, whose cultural matrices rest in indigenist contexts, since pre-columbian times. Likewise, we aim to talk about healers vegetalist in rural and urban areas phenomena, where we check techniques of healing and witchcraft in line with catholicism and european esotericism, in modalities allusive to the mythical and ritualistic reinterpretation of the consumption of "plants of power". Finally, we will indicate how such knowledges are re-signified in the light of contemporary south american models, allowing the dialogue between doctors, psychologists and shamans for the treatment of subjects affected by drug addiction.
\end{abstract}

Key Words: Ayahuasca. Shamanism. Vegetalism. Therapies. 


\section{Introdução}

$\mathrm{N}$

presente manuscrito aludimos para os fenômenos cosmológicos e terapêuticos associados ao uso da bebida ayahuasca em contextos ameríndios, buscando demonstrar as atribuições assumidas pelo chá em âmbitos indigenistas e vegetalistas, assim como possíveis reinterpretações culturais destes saberes na contemporaneidade, onde constatamos o aflorar de variegados modelos de terapia rutilados por preceitos anímicos inerentes ao perspectivismo dos povos tradicionais amazônicos (VIVEIROS DE CASTRO, 1979; 1992; 1996). Praticantes das "medicinas da floresta" os atores daqui, apesar das distinções, nutrem fortes conexões com os seres vivos e não vivos a habitar num mundo animado, do qual a complexidade lhes é demonstrada a partir do consumo ritualístico de substâncias psicoativas, dentre as quais se destaca a ayahuasca (WEISS, 1969; SISKIND, 1973; ARHEM, 1981; NARANJO, 1983; LUNA, 1986; TOWSLEY, 1988; GOW, 1991; 1996; LAGROU, 1991; 1998; MENDES, 1991; BELAÚNDE, 1992; LANGDON, 1994; 2002; OTT, 1994; OLIVEIRA, 2016).

De início, buscaremos compreender fenomenologicamente os universos simbólicos tradicionais, onde a beberagem assume histórico protagonismo na gestação de corpos, subjetividades e entidades, cujos encadeamentos repercutem nas mitologias, nos rituais, nas visões de mundo e outras formas de sociabilidade ancoradas no que Viveiros de Castro $(1979 ; 1992 ; 1996)$ conceituou de perspectivismo ameríndio. Visitaremos brevemente este conceito, uma vez que entendemos que o uso da ayahuasca, desde o contexto indigenista, encontra-se absorto em concepções anímicas, das quais encontramos peculiares noções a respeito da natureza, da cultura, da saúde, da doença, da vida e da morte; fenômenos interligados e elucidados pela práxis xamanística (ALMEIDA, 2002; KEIFENHEIM, 2002; LUZ, 2002).

Na sequência, apresentaremos nuances relativas à "feitiçaria terapêutica" fomentada por curandeiros vegetalistas - em territórios peruanos e colombianos - da qual notamos reconfigurações e reinterpretações das matrizes indígenas frente ao uso da ayahuasca e de outras "plantas de poder" (DOBKIN DE RIOS, 1972; 1973; LUNA, 1986; 2002; MACRAE, 1992; LABATE, 2011), assim como a emergência, em países da América Latina, de modelos terapêuticos voltados ao tratamento da dependência química e de outras patologias, permitindo-se ao diálogo construtivo entre medicinas da floresta e biomédicas (MABIT et al., 1992; MABIT, 1995; 2002; LABATE et al., 2009; MERCANTE, 2013; RICCIARDI, 2013).

\section{Perspectivas e ontologias ameríndias: Conhecendo "o berço da ayahuasca"}

Ao refletir sobre povos tradicionais ameríndios, Viveiros de Castro (1979; 1992; 1996) cunhou a hipótese do perspectivismo para compreensão etnológica dos habitantes da Amazônia desde tempos pré-colombianos. Para ele, o modo de pensar destes agrupamentos apresenta-se na qualidade de perspectiva através de um ponto de vista comum, uma vez a ideia de que o mundo e o universo são estanciados por humanos e não humanos capazes de vivenciar o mundo por perspectivas próprias. $\mathrm{O}$ aspecto primordial do ameríndio repousa na noção de "unidade dos seres". Nesta ótica, o pensamento vislumbra os âmbitos relacionais da 
existência, justificando a mobilidade das coisas da natureza, do cosmos e da cultura.

O perspectivismo, como teoria indígena, demonstra como humanos enxergam outros humanos, mas também animais, plantas, espíritos e fenômenos, que possuem perspectivismos próprios. As sociedades dos animais, das plantas e dos seres astrais organizam-se de modo semelhante às humanas, existindo, no universo ameríndio, a recorrência de perspectivas cruzadas. Os corpos são roupas a camuflar nos bichos, e em outros seres, sua essência humana apenas detectada por entes de mesma espécie, ou por agentes transespecíficos, como é o caso dos xamãs (VIVEIROS DE CASTRO, 1979; 1992; 1996).

Mitos ameríndios trazem referências à perda da humanidade por parte dos bichos, estando os esforços mitológicos voltados à demonstração de que apenas humanos conseguiram, ao longo da história, manter-se iguais na essência e aparência. A condição humana se faz presente como categoria divina, mantendo-se resguardada pelos "homens da floresta" devido ao seguimento de tabus, sansões e restrições, singularmente, no nível alimentar, onde a cultura, ao mesmo tempo em que conclama o que pode ou não ser ingerido vindica a dessubjetivação dos animais, antes do consumo, por meio de ritos com o propósito de "anular o espírito", originalmente humano, e transformar a carne em vegetal.

Viveiros de Castro $(1979 ; 1992 ; 1996)$ indicou que, paralelo ao mundo dos caçadores coexiste a práxis xamanística, pois xamãs são mediadores entre os seres e suas perspectivas. Em êxtase, o xamã adentra nas perspectivas extra-humanas, penetrando na carne dos outros seres, porém retornando ao plano ordinário para narrar experiências. Uma fenomenologia nativa voltada à significância dos processos sociais, que são estendidos aos domínios sobre-humanos. Devido ao fato de bichos, espíritos, plantas e pessoas conviverem no mesmo patamar sociocósmico, as divergências entre cultura e natureza afloram de dentro dos esquemas sociais, sendo à natureza uma agência amalgamadora da sociedade. Um sistema unificador, onde categorias e relações sociais são utilizadas para mapear o mundo e o universo

Lévi-Strauss (1962) auxiliou Viveiros de Castro (1979; 1992; 1996) no entendimento da mente ameríndia, que desenvolve distinções entre natureza e cultura, conquanto eles universalizem a cultura como fazendo parte da natureza do humano, contrariando nossas distinções entre humanos, animais e vegetais. A constatação de que animais, plantas e espíritos são pessoas abre margem para várias interpretações e ações. Uma delas é a outorga de capacidades aos elementos extra-humanos, dando-lhes faculdades para tornarem-se agenciadores do fazer social. A objetificação destes outros seres repousa nas suas realidades espirituais, mesmo porque são portadores de almas. Se for sujeito possui consciência de si e se tem consciência tem um espírito agenciado por este mesmo ponto de vista.

No Ocidente a posse de consciência é o que distingue humanos de agentes naturais, reservando-nos à humanidade hábil a nos isolar da cadeia bioecológica, pondo em evidência o fomento da cultura para domínio da natureza (LÉVISTRAUSS, 1962; VIVEIROS DE CASTRO, 1979; 1992; 1996). Por outro lado, nosso organismo nos interliga a outros seres por compostos bioquímicos, a exemplo do DNA. Fenômeno oposto dentre ameríndios, pois existe contiguidades metafísicas, ao passo em que nos deparamos com intercadências orgânicas, onde corpos diferentes representam roupagens diferentes e descartáveis. A condição humana é interiormente preservada, sendo a couraça fator delimitador e o espírito, humano por natureza, princípio amalgamador dos agentes no universo. 
Alguns autores vêm sinalizando para a relevância da corporeidade ameríndia, devido ao aspecto cosmológico alusivo às relações intersubjetivas e construções identitárias atreladas às performances e expressões corporais, basicamente expressas em alimentos e substâncias, além da estética manifesta nos adornos, músicas e marcas corporais (LÉVI-STRAUSS, 1962; VIVEIROS DE CASTRO, 1979; 1992; 1996; CLASTRES, 1980). Um uso semiótico do corpo, que delineia identidades num mundo animado em fluxo contínuo. Diferir o corpo surge como garantia de aquiescência identitária, pois particularizada a couraça - descartável do ponto de vista cosmológico - passa a ser fator de destaque e, ao mesmo tempo, de dessemelhança. O corpo é visto como lócus para o duelo entre humanidade e animalidade, manifestando-se como ferramenta primordial para a exibição social do indivíduo, porém também representando objeto de observação, estando à práxis estética da ritualística a representar o auge da animalização (VIVEIROS DE CASTRO, 1979; 1992; 1996).

A singularização do corpo favorece a objetivação do sujeito perante si e os outros, porém a subjetivação do corpo advém do contato interacional com outros planos da existência, para além da materialidade, estando o ameríndio a se permitir à culturalização pelas vias da natureza. Neste perspectivismo somático há forte exaltação na produção de corpos, onde a memória do universo e dos grupos estandardiza-se na carne e na mente.

Os espíritos antepassados são criaturas replenas de subjetividades, intenções e propriedades específicas, quase sempre, votadas às curas, embora também possam estar atrelados às manifestações patológicas (CLASTRES, 1980). Por terem se desprendido de seus corpos, os mortos não são mais humanos, porém suas almas são atraídas pela couraça de outros entes animais e vegetais, adquirindo nova perspectiva perante o fenômeno da possessão espiritual. A morte significa a metamorfose do falecido em animais (ou vegetais) cuja alma - não mais humana, após o desencarne - propende-se à humanidade, apenas na posterior possessão de uma couraça, cuja essência ontológica volta-se a se tornar humana, adquirindo perspectiva humana, mesmo estando no domínio dos corpos de outros entes.

Não só animais e plantas ficam a mercê do ataque de espíritos na busca por humanidade. Como observa Viveiros de Castro (1979; 1992; 1996), nos âmbitos fenomênicos e sobrenaturais o encontro entre subjetividades pode gerar desvios e anomalias, nas quais seres humanos chegam a ser dominados, tendo espíritos e corpos capturados por perspectivas que lhes são alheias (CLASTRES, 1980). Ao ser submetido a uma ontologia espiritual o ator despreparado pode assumir, temporária ou eternamente, a perspectiva dos desencarnados.

Para Viveiros de Castro $(1979 ; 1992 ; 1996)$ apenas os xamãs e feiticeiros estariam preparados para trafegar nos transmutados universos interligados à existência humana, assumindo perspectivas alheias e conhecendo-as melhor, por se permitirem à afetação de realidades não ordinárias, porém sem perderem a condição de pessoa. Os protagonistas dos mitos ameríndios evidenciam tais atores e suas descobertas ao alcançarem estados de êxtase, onde lhes é possível adentrar neste influxo de corpos, espíritos, doenças, pessoas, plantas, curas, animais e demais elementos imersos numa mesma perspectiva cosmológica e social. 


\section{Ayahuasca: Uma "medicina da floresta"}

A ayahuasca vem sendo referenciada em seu uso milenar devido à relevância ocupada na vida dos povos tradicionais situados no espaçamento geográfico e cultural, que interliga parte do território de 06 países sul-americanos, entre os quais o Peru, o Equador, a Colômbia, a Venezuela, o Brasil e a Bolívia; unidos desde as nascentes do Rio Ucayali na Cordilheira dos Andes até as extensões do Rio Negro na Colômbia, na Venezuela e no Brasil, representando importante área habitada por agrupamentos que compactuam de semelhantes cosmologias (ALMEIDA, 2002; KEIFENHEIM, 2002; LANGDON, 2002; LUZ, 2002).

Luna (1986) indicou a existência de 72 grupos indígenas usuários da bebida na Amazônia Ocidental, enquanto Naranjo (1983) revelou, através de achados arqueológicos, que o uso ameríndio do chá teve início no Século VI a.C. Do imaginário destes povos observamos práticas, mitologias e cerimoniais voltados à ingestão do chá com finalidades terapêuticas, mas também como forma de alçar disciplina e controle, tanto de corpos, quanto de espíritos e sociedades. Grande parte das civilizações que compactuam destes saberes está inserida num tipo de religiosidade, identificada por Andrade (1995), pela característica agrária e andina imersa na concepção de "Pacha Mama", que engloba 03 troncos linguísticos locais: Quíchua, Purina e Aimará, estendendo-se por vasto território amazônico, antes habitado pelos Incas, em terras colombianas, equatorianas, peruanas, bolivianas, chilenas e argentinas.

O preparo do chá nos reporta a técnicas ancestrais, sendo reconhecido o poder do xamã por sua capacidade em produzir a beberagem. O "vinho das almas" - como a ayahuasca também é conhecida- é preparado a partir de duas espécies vegetais: o cipó Banisteriopsis Caapi da família das Malpighiaceae, junto com as folhas da Rubiaceae Psychotria, sobretudo, a Psychotria viridiis ${ }^{l}$. Em 1851 o cipó foi classificado pelo botânico Richard Spruce, inicialmente, denominando-o de Banisteria caapi ${ }^{2}$ ao longo de expedições na Amazônia brasileira, equatoriana e venezuelana de 1849 a 1864 (MACRAE, 1992; LABATE, 2004; MCKENNA, 2005). Ele empreendeu coletas mediante convívio com grupos do tronco linguístico Tukano, que habitavam a área conhecida por Ipanoré situada no baixo Rio Uapés.

A priori, o alcalóide identificado no cipó caapi foi denominado de telepatina, embora também tenha sido epitetado por yageína, banisterina e mais recentemente harmina, contendo harmalinas e outros metabólitos (ESCOBAR, 2012). Foi apenas em 1970, que o botânico Ghillean Prance categorizou a outra planta que compõe a beberagem; as folhas do arbusto Psychotria viridis, ao mesmo tempo em que isolou o alcalóide 4-Metoxi-dimetiltriptamina (a DMT); substância considerada potente psicoativo.

Ao lidarem com "substâncias sacramentais" ameríndias - como é o caso da ayahuasca - parte dos pesquisadores propende-se à utilização da terminologia enteógeno, por considerarem-na mais oportuna e respeitosa, no que tange às experiências narradas, tanto pelos homens da floresta, mas também por caboclos ribeirinhos e habitantes dos centros urbanos (LABATE, 2004). Hofmann et al.

${ }^{1}$ Pesquisadores, entre eles: Schultes \& Hoffmann (1992) e Luna (1986) demonstraram o acréscimo de plantas aditivas nos extratos indígenas, entre as quais o Ají (Capsicum frutescens), a Catahua (Hura crepitans), a Kana (Sabicea amazonensis), a Pulma (Calathea veitchiana), o Sananco (Tabemaemonta sananho), o tabaco (Nicotiana rustica), a folha de coca (Erythroxylum coca), o Rami (Lygodium venustum), dentre outros vegetais acrescentados ao chá, no intuito de manifestarem propriedades específicas, como, por exemplo, cantar, fortalecer o corpo, reduzir ou aumentar visões, promover desintoxicações, servir como estimulante e outros fins.

${ }_{2}^{2}$ A planta foi reclassificada posteriormente, chegando-se à nomenclatura atual Banisteriopsis Caapi. 
(1980) propuseram a denominação enteógeno para designar psicoativos visionários ingeridos com o propósito de contatar o "plano divino", atingindo uma complexa percepção das coisas em contínua relação no mundo e no universo. Em grego o prefixo "entheos" pode ser interpretado como alguma coisa (neste caso um corpo) inspirado ou incorporado por um deus ou entidade extra-humana, enquanto a desinência "geno" remete-nos às expressões: gestação e produção de alguma coisa, de modo que enteógeno reporta-nos à sentença "deus dentro de si".

Outros autores não abrem mão das expressões "plantas de poder" ou "plantas professoras" por julgarem-nas eficazes, mediante a aproximação das "categorias nativas", assim como dos significados atribuídos pelos atores às substâncias cultuadas e experienciadas em seus efeitos visionários (LUNA, 1986; MOURE, 2005; LIRA, 2009; 2016). Aqui, plantas e animais são considerados antepassados desencarnados possuidores de almas humanas (VIVEIROS DE CASTRO, 1979; 1992; 1996). É desta relação com a natureza que os povos da floresta conseguem alcançar a cura, perante o afastamento da doença, sobretudo, a partir de ritos com ayahuasca conduzidos por xamãs atuantes como médicos populares, trabalhando na intenção de curar. Por ser uma "planta mestra", a ayahuasca também é considerada "la medicina", sendo recorrida nos processos de cura, diante de situações, onde receitas caseiras não obtiveram resultado. O uso do chá vai além da cura de patologias físicas, sendo utilizado como fator defensor contra os ataques do plano metafísico.

Ao nos debruçarmos sobre a tônica da cura ayahuasqueira ameríndia, nos deparamos com ampla similaridade simbólica, ritualística e mitológica dentre civilizações locais. Apesar das divergências étnicas e culturais, o âmago das práticas xamanísticas procede, não apenas na restauração do equilíbrio dos processos orgânicos, mas na atenção ampliada aos fatores englobantes da vida, incluindo a psique e tudo considerado transcendente à condição humana. Saez (2008) observou as finalidades do chá dentre indígenas, onde o mesmo adquire função de agente curador, surtindo benefícios nos organismos adoentados, embora os xamãs consagrarem a substância isoladamente e durante sua viagem astral consigam diagnosticar patologias nos corpos, assim como extraí-las da "matéria" do paciente, mediante batalhas performáticas e negociações com entidades espirituais.

As tradições dos povos de língua Pano, Aruák e Tukano foram estudadas por etnógrafos e etnólogos, que chegaram a conclusões fortuitas referentes às semelhanças compactuadas por estes agrupamentos étnicos, especialmente, em relação às suas perspectivas e concepções de mundo (WEISS, 1969; SISKIND, 1973; ARHEM, 1981; TOWSLEY, 1988; LAGROU, 1991; 1998; MENDES, 1991; BELAÚNDE, 1992; LANGDON, 1994; 2002; OTT, 1994; LUZ, 2002; OLIVEIRA, 2016). O uso da ayahuasca e a importância da bebida na vida destes povos surgem como elo de inter-relação simbólica referente às mitologias, filosofias e visões de mundo direcionadas ao convívio dos humanos com a natureza.

Aqui os atores vêem a natureza e seus elementos como algo animado, repleno de espíritos antropomorfizados a vagar pelo mundo dos vivos, na intenção de incorporarem-se em plantas, animais ou pessoas. Os xamãs figuram hábeis personagens mediante vislumbre e negociação com entes extra-humanos, sendo capazes de, após o consumo da ayahuasca, transformar-se em seres da floresta, assumindo a perspectiva dos mesmos (VIVEIROS DE CASTRO, 1979; 1992; 1996; CLASTRES, 1980). O cipó Banisteriopsis caapi mostra-se presente nas cosmologias, fomentando o dinamismo destas sociedades, que trazem consigo teorias plausíveis sobre a natureza, o homem, o mundo, o cosmos e a cultura. 
Lagrou (1991; 1998) e Oliveira (2016) demonstraram que dentre os $\mathrm{Ka}$ xinawá (Huni Kuin) de língua Pano - onde a bebida é denominada nixi pae - a concepção de natureza é semelhante ao conceito grego de physis, pois elementos naturais são possuidores de perspectivas, sendo a cultura uma extensão da natureza e de suas ordens refletidas na vida e nas sociedades de homens, plantas e animais. Na mitologia Huni Kuin, aludimos para a relevância cosmogônica e cosmológica da jibóia Yube e suas relações com os fenômenos ontológicos alusivos ao devir, mas também às transmutações, aos translados entre os planos da existência e à incorporação dos yuxins; momentos nos quais a serpente cósmica Yube é ingerida por humanos quando consagram o nixi pae. Dessa feita, torna-se possível ver o mundo em sua complexidade e participar das eminentes conexões universais, pois a constatação da presença de Yube no corpo do bebedor simultaneamente figura entrada do bebedor no corpo e no mundo de Yube (LAGROU, 1991; 1998; OLIVEIRA, 2016).

Nos planos não ordinários da consciência o xamã Kaxinawá adentra nos "Encantos", interagindo com os yuxins; entidades incorporadas em animais e plantas, que também são Huni Kuin ("gente como a gente") (LAGROU, 1991; 1998; OLIVEIRA, 2016). Durante o êxtase, é possível compactuar o sentimento de igualdade entre vivos e não vivos, estando às visões do nixi pae relacionadas aos sonhos, que representam formas não ordinárias de relacionar-se com planos metafísicos e naturais regidos por Yube. A "purgação do nixi pae", como descrito por Keifenheim (2002), adquire formas distintas, de modo que o bebedor pode vislumbrar na vomição insetos, sangue, fogo, vísceras e penas. Ao serem tomados pela purga e suas visões imagéticas os sujeitos têm a sensação de serem remetidos para dentro das imagens, assim como tais imagens adentram no corpo do indivíduo, havendo uma fusão sinestésica; considerada um estado momentâneo de falecimento e morte simbólica.

Entre os Yaminawá - também de língua Pano - a ayahuasca, ou shori, permite que entidades extra-humanas manifestem-se nos xamãs, fazendo-os cantar e dançar (TOWSLEY, 1988). A melodia promove cura, pois o próprio shori e a música dos Encantados estão associados ao recobro físico e espiritual. Aqui, cantos, incorporações, danças, doenças, saúde e visões mantêm relações dialógicas, pois as visões promovidas pelo shori estão relacionadas à dinâmica do mundo espiritual; esfera existencial visitada e vigiada por xamãs. Atinando-se à origem dos infortúnios - remetida ao plano metafísico - o xamã Yaminawá exercita visões seletivas do plano espiritual, no intento de enxergar certas coisas em detrimento de outras. Daí a importância das canções; elementos que asseguram visões e guiam os feiticeiros por caminhos na busca do recobro. O êxtase representa momento ideal para aquisição de sabedoria para a diagnose terapêutica, instante no qual se obtêm conhecimento sobre corpos e espíritos. Uma ação que permite ao xamã Yaminawá fornecer aos pacientes remédios e dietas.

Siskind (1973), Schultes \& Hoffmann (1992), Ott (1994) e Luz (2002) constataram o papel da ayahuasca (ondi) nas cosmologias Sharanawá, também pertencente ao tronco Pano, onde ritos de cura têm poder de sintonizar as visões dos xamãs com os sonhos dos pacientes, estando os cantos relacionados às terapias. Weiss (1969), Gow (1991; 1996) e Mendes (1991) ratificaram a relevância da bebida kamarampi - como o chá é conhecido entre os Ashaninka de língua Aruák - cujas propriedades vomitórias apresentam-se cruciais à cura (LUZ, 2002).

Belaúnde (1992) e Luz (2002) certificaram-se de que a cultura do povo Airopai de língua Tukano propende-se ao consumo ritualizado da ayahuasca (yagé) acompanhado pelo vislumbre das plantas enquanto possuidoras de espíritos com 
características antropomorfizadas, cujas realidades só podem ser acessadas por meio do yagé. Entre os Makuna, também do tronco Tukano, percebemos o uso do chá (kahi ide) coadunar-se com concepções nativas sobre o corpo, a saúde e a doença (ARHEM, 1981). Inebriados pelo kahi ide, os xamãs conseguem proceder em suas diagnoses e curas místicas, porém também são capazes de açodar o fadário pós-morte dos humanos desencarnados, pois acreditam que as visões remetem aos planos espirituais percorridos pela alma dos sujeitos após suas mortes.

Langdon $(1994 ; 2002)$ verificou que o uso da ayahuasca ( $i k o$ ) dentre o povo Siona de língua Tukano interfere na vida e na organização dos agrupamentos influenciados pelos entes "do outro lado". Os planos metafísicos e materiais se complementam, apresentando-se como imagens especulares, de modo que todas as coisas que acontecem aqui deste lado repercutem no plano astral e vice-versa. Há ênfase no poder das "forças sobrenaturais" capazes de interferir em organismos e sociedades, podendo trazer discórdias, doenças, falecimentos, catástrofes, anomalias, escassez alimentar e demais fenômenos "anormais".

Segundo Luz (2002), outro aspecto semelhante relativo ao uso da ayahuasca dentre estas populações apresenta-se no caráter pedagógico conferido à beberagem tida como possuidora e transmissora de conhecimentos e saberes fundamentais à vida, especialmente, no tocante às questões morais e comportamentais dos atores frente às relações mantidas com outros sujeitos, mas também com os ancestrais, os seres da natureza e os espíritos. Aqui, também existe forte convicção nos propósitos terapêuticos do chá, sendo evocado como agente xamanístico para as diagnoses, além de representar potente remédio prescrito para o alcance do recobro da saúde em praticamente todos os grupos étnicos acima citados.

Langdon (1994; 2002), Wright (1998), Almeida (2002) e Keifenheim (2002) observaram que o consumo da bebida não se restringe aos xamãs, posto que não xamãs também entram em contato com os mistérios da ayahuasca, cujas propriedades têm o poder de atuar sobre corpos, mentes e espíritos, facilitando a circulação dos sujeitos entre planos sobrenaturais e realidades ordinárias. As visões da ayahuasca são tidas como semelhantes aos estados de sonho e morte, contudo as alterações perceptivas sejam controláveis pelo bebedor. Neste sentido, os enteógenos, assim como os cantos, os sonhos e as danças configuram técnicas úteis à modificação corporal e mental, devido à sua capacidade de transmutar indivíduos nos tempos, espaços e dimensões de uma possível "existência universal".

\section{A magia ayahuasqueira dos vegetalistas}

A população mestiça em territórios peruanos e colombianos, assim como a prática de seus curandeiros ao longo de ritos de cura - na floresta e nas metrópoles - com ayahuasca e plantas de poder foram investigados por Dobkin de Rios (1972; 1973), Luna (1986; 2002), MacRae (1992) e Labate (2011), que demonstraram ser o vegetalismo um tipo de medicina popular, tendo como base os saberes adquiridos das plantas, incluindo a arte de cantar e curar, além da noção de ataque ou proteção contra malefícios, a prática de dietas e tabus e a comunicação do curador com planos extra-humanos. Como foi sinalizado por MacRae (1992), dentre esta população encontramos diversos curandeiros, sendo os vegetalistas representantes de um subgrupo desta categoria abrangente, amiúde, intitulados 
de "mestres", “doutores", "velhinhos", "bancos" 3 e "vovozinhos". Práticas vegetalistas podem ser encontradas dentre as populações interioranas e citadinas do Peru e da Colômbia, estando em processos de reinterpretações de tradições indígenas, cristãs e esotéricas (LABATE, 2011).

Conforme indicado por MacRae (1992), Luna (2002) e Labate (2011), constatamos, que a prática vegetalista surgiu em território amazônico do final do Século XIX para o início do XX período, no qual observamos o contato dos seringueiros advindos do Peru e de outros países com as populações indígenas e caboclas, que já haviam passado por processos de colonização e catequização. O xamanismo vegetalista voltado para a cura, de acordo com Gow $(1991$; 1996) e Labate (2011), é identificado como produto cultural relativo aos contatos interétnicos e fluxos migracionais da cidade para a floresta e vise versa.

Macrae (1992) detectou que mesmo diante das mudanças inerentes aos processos de colonização, catequização, exploração da borracha e migrações - inicialmente da floresta para a cidade e depois da cidade para a floresta - alguns elementos xamanísticos permaneceram dentre vegetalistas, embora tenham passado por influências de outros sistemas simbólicos como vertentes do catolicismo rural e do esoterismo europeu. Os saberes sobre plantas foram "preservados" pelos curandeiros, assim como a concepção ameríndia sobre mundo e corpos em relação com o cosmos e o plano espiritual (VIVEIROS DE CASTRO, 1979; 1992; 1996).

O termo vegetalista passou a ser designado aos curadores, que obtiveram conhecimentos sobre corpos, doenças e curas a partir dos espíritos de "vegetais professores" capazes de instruírem os xamãs em prol da cura, mas também do desvelo referente aos segredos do universo. Vegetais também designados por “doutores”, pois aos seus espíritos são outorgados os princípios da sabedoria fenomenicamente unificada numa complexa e abrangente sapiência médica, religiosa e mágica transmitida por meio de cantos e demais sonoridades, pela performática salivação acompanhada da ejeção de "corpos patológicos" (setas e virotes) do organismo infortunado, além dos estados ampliados de consciência, que representam elementos centrais às terapêuticas vegetalistas (DOBKIN DE RIOS, 1972; 1973; LUNA, 1986; 2002; MACRAE, 1992; LABATE, 2011).

Embora o mais importante destes professores seja a ayahuasca, encontramos, tal qual no contexto indigenista, a presença de "plantas aditivas" inseridas pelos vegetalistas à bebida - feita à base do cozimento das folhas da Psychotria viridis, junto com o cipó Banisteriopsis caapi - tendo em vista, que os mesmos compactuam da crença de que outros vegetais de poder, quando acrescentados à "planta mãe", além de tornarem-na mais potente, facilita o contato do curandeiro e dos doentes com o espírito destas outras plantas, também possuidoras de almas, perspectivas e autonomias acessadas durante as Sessões da ayahuasca; "planta mater" que permite a manifestação de outros espíritos vegetais a ela agregados.

Vegetalistas podem ser denominados feiticeiros ou bruxos. Neste sentido, estas categorias são utilizadas para definir sujeitos envolvidos com a magia voltada para o "mal", havendo batalhas no mundo dos vegetalistas contra tais forças frente à cura dos "clientes". A doença pode ser inserida no corpo por um "brujo" mal intencionado, sendo capaz de ser sanada perante atuação de um curandeiro poderoso (banco). No universo dos feiticeiros, podem existir "bancos do bem" e "bancos do mal", a depender das formações iniciáticas, condutas e escolhas do vegetalista no decorrer de sua trajetória biográfica (MACRAE, 1992).

3 De acordo com MacRae (1992), o termo "banco" é empregado aos práticos vegetalistas, que possuem vasto conhecimento, figurando "bancos para assentamento" dos poderes sobrenaturais. 
A noção de "Encanto" é cara à prática vegetalista, adquirindo, segundo Labate (2011), múltiplos significados. O Encanto, ou Encantado, pode representar uma alma, ou qualquer ente possuidor de consciência capaz de estipular interrelações com os curandeiros e seus pacientes, como também Encanto pode nos remeter a territórios metafísicos, onde habitam as entidades, aos objetos mágicos "benignos" ou "malignos", desde que a coisa em si tenha uma autonomia espiritual. Contam muitos vegetalistas sobre os fatos ocorridos no ínterim de suas iniciações, momento no qual entraram em contato com espíritos a ofertá-los dons e presentes de vários tipos "benignos" ou "malignos" (LUNA 1986; 2002; MACRAE, 1992). O neófito, em processo de passagem, tem o arbítrio para escolher as dádivas ofertadas, apesar da narrativa dos vegetalistas trazer a concepção da maior facilidade em se tornar um brujo do que um banco, na medida em que para testar a índole do sujeito, as entidades obsequiam os neófitos com "poderes do mal" e, caso o sujeito se impressione, tornar-se-á um brujo.

No desenrolar dos encadeamentos iniciáticos é que os presentes "benignos" voltados ao alcance do recobro da saúde, do sucesso profissional e do amor são ofertados pelas entidades aos neófitos, que dispõem de amplo conhecimento, pois passam a compreender e a lidar com as forças a eles apresentadas e ofertadas, no intuito do vegetalista proteger seus clientes e a si mesmo contra os ataques de forças a serviço de brujos (DOBKIN DE RIOS, 1972; 1973; LUNA, 1986; 2002; MACRAE, 1992; LABATE, 2011). O ímpeto para adesão ao "lado negativo" é uma constante, considerando-se, que o acúmulo dos poderes do feiticeiro tende a influenciá-lo às “práticas incorretas". De acordo com Macrae (1992), o fomento de hábitos moralmente condenáveis, como consumir drogas ilícitas e bebidas alcoólicas, são suscetíveis a conduzir feiticeiros para o "lado negativo", sendo comuns histórias de vegetalistas, que prestaram serviços às "forças do bem", tornando-se brujos com o tempo.

Normalmente os feiticeiros iniciam no xamanismo vegetalista devido ao acometimento de patologias desacreditadas pela medicina oficial. Não conseguindo cura, o futuro curandeiro busca os serviços de vegetalistas ou ingere a bebida por conta própria. Entrando em contato com os mistérios do chá e de outras plantas de poder, os antigos infortunados, quando se curam, narram o ganho de um gradativo dom de curar. Os procedimentos da cura vegetalista giram em torno de dietas cercadas por abstinências e tabus. Há, por parte de curadores e enfermos, a ingestão de "plantas purgativas" - anterior ao consumo de plantas de poder - com o objetivo de "limpar" os corpos, para que os vegetais doutores possam neles atuar. Esta ação propende-se à precaução, no tocante aos efeitos adversos, que podem acometer o sujeito durante o ritual, devido ao consumo de alimentos e toxinas, cujos restos são expelidos na forma de vômito e fezes (DOBKIN DE RIOS, 1972; 1973; LUNA, 1986; 2002; MACRAE, 1992; LABATE, 2011).

O cumprimento das dietas leva os bancos ao caminho da sabedoria, tornando seus corpos poderosos, sem contar na atribuição dada aos procedimentos dietéticos frente ao melhor funcionamento de mente e espírito, aguçando os sentidos e a capacidade de memorização dos ensinos dos enteógenos. Praticando a dieta, o conteúdo de sonhos e visões fica mais nítido, pedagogicamente falando, mesmo porque a comunicação com os espíritos curativos não sofre interferência de outras "forças" estranhas à ordem terapêutica (DOBKIN DE RIOS, 1972, 1973; LUNA, 1986, 2002; MACRAE, 1992; LABATE, 2011). No contexto vegetalista dietas são seguidas, tanto por curandeiros, quanto por pacientes, antes da consagração da ayahuasca, uma vez que a transgressão destes preceitos pode intervir 
no efeito da beberagem, chegando à inviabilização de sua potencialidade terapêutica.

Ritos vegetalistas em torno da cura incluem a manipulação performática de cunho conciliador frente às forças espirituais, no intuito de aliviarem os queixumes dos clientes, sejam os mesmos de ordem orgânica, psíquica, espiritual, emocional, financeira ou moral. Apesar dos rituais apresentarem variações de curandeiros para curandeiros, o universo vegetalista se volta à manutenção de certas matrizes rituais e místicas em comum, assim como, determinados símbolos trazidos cerimonialmente no rezar, na contação de histórias, no consumir a ayahuasca e cantar para forças naturais e extranaturais (LABATE, 2011).

Após a consagração do chá, os curandeiros adentram em processos de incorporação propiciados pelas entidades evocadas. Males orgânicos são exprimidos em objetos mágicos (setas e virotes) ou animais (cobras e escorpiões), estando o curador atento à manutenção de sua proteção e de seus pacientes. Acredita-se que a fumaça do tabaco fomenta uma armadura mágica; a arkana, reconhecida como instrumento de defesa, bloqueando corpos e impedindo o ataque de "vetores malignos". A arkana, conforme Luna (1986) e MacRae (1992) adquire variadas formas vislumbradas pelos vegetalistas na figura de animais, arcanjos ou soldados a guerrear contra forças do mal. No meio da peleja, os curadores são socorridos por entidades antropomórficas (animais e vegetais), assim como pelas almas dos antepassados (mestres e pajés da cura), embora possam ser auxiliados por médicos, pensadores desencarnados e entidades extraplanetárias. O curador pode ou não incorporar entidades, quando não, eles dialogam com elas, recebendo conselhos, mas também cânticos mágicos (ícaros) e outros presentes como a saliva (yachay) e os virotes para proteção.

Elementos cruciais à arte dos vegetalistas, e que os acompanham desde os tempos iniciáticos, que são os períodos no quais realizaram dietas longe da sociedade. Momentos onde se permitiram aos ensinos das plantas transmitidos na forma de visões e ícaros a comprovarem a força e o poder da natureza, o que pode ser utilizado tanto para a proteção e defesa, quanto para a causa do mal. Os ícaros $\left(\right.$ yakaray $\left.^{4}\right)$ acompanham as ações xamanísticas, estando ou não as práticas destinadas ao consumo de enteógenos. Para MacRae (1992) a qualidade do curador repousa em sua habilidade na entoação de cânticos capazes de fomentar visões durante ritos. Um saber adquirido conforme o trilhar de cada curador e que os diferencia, chegando a criar rivalidades nos planos místicos ou cotidianos (LABATE, 2011).

Para Labate (2011) o vegetalismo encontrado atualmente, principalmente nas urbes peruvianas, enaltece as práticas de cura a partir de concepções psicológicas, cristãs e ocidentalizadas de autoconhecimento e desenvolvimento pessoal em detrimento da magia e da feitiçaria, apesar de serem temáticas recorrentes nos relatos de novos e antigos curandeiros. Amiúde, os bancos antigos estão mais próximos dos conceitos ameríndios, enquanto os mais jovens tendem à inclinação esotérica inspirados em filosofias europeias. 


\section{Saberes médicos e vegetalistas no tratamento de toxicomanias}

Atualmente os saberes dos xamãs e vegetalistas vêm sendo reinterpretados por modelos terapêuticos em países sul-americanos encarregadas no tratamento da dependência química. Os pesquisadores vêm demonstrado interesse nestas medicinas tradicionais capazes de manifestarem nos sujeitos estados de consciência ampliados e controlados hábeis à cura de adicções (MABIT et al., 1992; MABIT, 1995; 2002; LABATE et al., 2009; MERCANTE, 2013; RICCIARDI, 2013). Em contexto peruviano, Chiappe et al. (1985) constataram a ocorrência de tratamentos de alcoolistas, que vêm sendo desenvolvidos por grupos da Costa Norte peruana inspirados no uso da mescalina encontrada no cacto wachuma.

Em solo peruano detectamos comunidades terapêuticas diversas, em especial os Centros: Takiwasi ${ }^{5}$, Sonccowasi e Situlli ${ }^{6}$ que se utilizam das práticas vegetalistas para o recobro de dependentes, associando estes saberes com os procedimentos da psicologia e da medicina (MABIT, 1995; RICCIARDI, 2013; LIRA, 2016). Em se tratando de comunidades terapêuticas sul-americanas e seus "trabalhos de desintoxicação" mediante uso da ayahuasca, Lira (2016) alude para a existência da Fundación El Emílio ${ }^{7}$ (situada na cidade argentina de Rosário), a Fundación Mesa Verde ${ }^{8}$ (localizada na Argentina, em Córdoba) e o Instituto Espiritual Chamânico Sol de La Nueva Aurora ${ }^{9}$ (em Montevidéu no Uruguai).

Entidades, onde há relação entre práticas xamanísticas e oficiais, principalmente, advindas das áreas de saúde, psicologia e terapia ocupacional. Os pesquisadores vêm dando atenção ao Centro Takiwasi, em Terapoto no Perú, fundado pelo médico francês Dr. Jaques Michel Mabit em 1992, após iniciação e aprendizado junto aos curandeiros, onde elaborou um modelo capaz de incluir múltiplas práticas de cura. Pouco tempo após sua fundação, a Takiwasi recebeu apoio de Órgãos de Saúde Coletiva locais. Inicialmente, obteve subsídios da União Europeia e do Governo Vasco, sendo até hoje auxiliado pelo Ministério de Educação do Peru e do Centro de Información y Educación para la Prevención Del Abuso de Drogas.

O modelo Takiwasi figura meio psicoterápico singular, pois tamanha agregação de elementos da medicina mestiça com os conceitos biomédicos e psicológicos, no tocante ao tratamento de dependências, traz implícita a concepção de que o uso e o abuso em psicoativos representam problemas secundários, sendo suas raízes detectadas nos casos envolvendo caos nas "esferas espirituais"; condições levadas seriamente em consideração (MABIT et al., 1992; MABIT, 1995; 2002; LABATE et al., 2009; MERCANTE, 2013; RICCIARDI, 2013).

Em quíchua, a palavra Takiwasi pode ser traduzida pela expressão "casa que canta". O paradigma desta comunidade repousa num tripé, cujas bases estão ancoradas nas dietas (isolamento e manutenção de jejuns), nas purgações (propiciadas pela ingestão de plantas depurativas) e na consagração da ayahuasca. $\mathrm{O}$ cotidiano da clínica é repleto de dinâmicas de grupo, oficinas e sessões psicanalíticas (RICCIARDI, 2013). Os pacientes ficam internados durante o9 meses em estado de reclusão, onde ingerem ayahuasca e outras plantas depurativas, como

5 Maiores detalhes disponíveis em: https://bit.ly/2nYARs9. Data de acesso: 20/04/2019.

${ }^{6}$ Sobre o Centro Situlli consultar: https://bit.ly/2MAGGcV Data de acesso: 20/04/2019.

7 Outras informações acessar: https://bit.ly/2Pijlvj. Data de acesso: 20/04/2019.

${ }^{8}$ Detalhes podem ser consultados em: https://bit.ly/2Mn8UIQ. Data de acesso: 20/04/2019.

9 Maiores informações no link: https://bit.ly/2LqTl1R. Data de acesso: 20/04/2019. 
é o caso da Yawa panga (Aristolochia didyma). Os Trabalhos feitos com os vegetais complementam-se às psicoterapias, oficinas e à própria rotina dos internos.

A ingestão de plantas vomitórias - dias antes da consagração da ayahuasca - por parte dos pacientes tem como objetivo a "limpeza" do corpo devido ao anterior uso abusivo de psicoativos, cujas toxinas são expelidas. A função secundária dos vegetais eméticos estaria ainda - conforme os terapeutas da Takiwasi relacionada à redução, ou, até mesmo, extinção dos sintomas das síndromes de abstinência, pois, após as purgações, os sujeitos afirmam sentirem-se aliviados no tocante aos quadros de ansiedade, compulsão e depressão devido à ausência de sua(s) substância(s) problema (MABIT et al., 1992; MABIT, 1995; 2002; LABATE et al., 2009; MERCANTE, 2013; RICCIARDI, 2013).

Os vegetais professores são administrados individualmente ou em grupos, porém sob supervisão da equipe de médicos, curandeiros, psicólogos e terapeutas, sem contar com o fato de que outros saberes e práticas coadunam-se ao tratamento, dentre os quais: a ergoterapia, o yoga, a biodança, terapias transpessoais, oficinas artísticas e esportivas, além de ritos e preces católicas (RICCIARDI, 2013). A atuação dos vegetalistas durante as Sessões com ayahuasca ocorre através da entoação de ícaros, sopladas de fumaça de tabaco ou de essências nos pacientes, além das chupadas dos corpos patológicos (LABATE et al., 2009).

Ricciardi (2013) demonstrou a relevância do modelo Takiwasi para a ampliação de perspectivas médicas, psicológicas e antropológicas, especialmente, no que toca à relação entre pacientes, terapeutas e xamãs, pois aqui encontramos vários agentes, incluindo pacientes e plantas, atuando nos processos curativos. Quando se permite dialogar com outros saberes e profissionais, o modelo estipula uma crítica às instituições destinadas ao tratamento oficial de dependentes, nas quais os sujeitos são demovidos da participação terapêutica, estando passivos e dependentes de terapeutas, instituições e fármacos (MABIT et al., 1992; MABIT, 1995; 2002; LABATE et al., 2009; MERCANTE, 2013; RICCIARDI, 2013).

Na Takiwasi, os terapeutas delegam o abuso de substâncias por parte dos indivíduos a um suposto vazio por eles experienciado em suas vidas. Há uma concórdia entre os atores da cura, particularmente psicólogos, de que humanos sentem a "necessidade natural" de alterar suas consciências, buscando nos psicoativos o alcance do êxtase (MABIT et al., 1992; MABIT, 1995; 2002). No caso de uso problemático de substâncias, o dependente buscaria auferir uma "ordem de comando" inexistente em suas vidas, tendo em vista possíveis ausências paternas (MABIT et al., 1992; MABIT, 1995; 2002). Ao ter acesso aos tratamentos na casa que canta - afirmam os terapeutas - os internos conseguem acessar uma "ordem universal" encontrada dentro do sujeito e que passa a norteá-lo, fazendo com que o mesmo assuma nova identidade por meio do acesso a outras perspectivas para além do abuso de psicoativos. Ao atingir o êxtase, por meio dos enteógenos e de forma controlada, o antigo abuso de substâncias, na lógica de pacientes e terapeutas, inclinar-se-ia à perda de sentido.

Atualmente a Casa funciona como albergue para sujeitos do sexo masculino, cuja faixa etária varia dos 20 aos 40 anos. $77 \%$ dos pacientes vêm de países da América Latina, enquanto $13 \%$ são estrangeiros europeus e norte-americanos. 10\% vêm de outros países e continentes (RICCIARDI, 2013). A Takiwasi oferece ainda outros serviços destinados aos sujeitos não acometidos por dependências, como é o caso das dietas e dos Seminários propostos aos atores na busca de outras curas propiciadas pelas medicinas ameríndias. 
O tratamento para dependentes representa eixo crucial da comunidade, onde permanecem os pacientes em recuperação ao longo de 09 meses considerado período de "gestação fetal", pois passados os processos individuais, os sujeitos afirmam terem adquirido nova vida como se estivessem encubados na casa que canta. O tratamento é pago mensalmente, porém existam chances de a instituição propiciar tratamentos gratuitos, especialmente, em se tratando de atores menos favorecidos e de nacionalidade peruana.

O modus operandi da "clínica enteogênica" baseia-se no diálogo entre os vegetais professores com os pacientes absortos em estados ampliados de consciência. Neste contexto, a ayahuasca favorece experiência unificadora, que gradualmente vai conduzindo os pacientes a ensinos e conhecimentos sobre si, posicionando-os numa realidade mais ampla (MABIT et al., 1992; MABIT, 1995; 2002; LABATE et al., 2009; MERCANTE, 2013; RICCIARDI, 2013). O modelo Takiwasi tende à mudança na concepção de pessoa, sentida não mais pelo prisma da organicidade, onde o corpo era visto como objeto pertencente ao homem, mas, justamente o contrário; o sujeito (alma ou consciência) passa a ver-se como possuído num corpo material, que, em seu âmago encarna uma espiritualidade iminente. Daí a relevância da transcendência na tentativa de "dissolução do Eu" para ajustamento do sujeito ao todo mais amplo (MABIT et al., 1992; MABIT, 1995; 2002).

O preparado extraído do cozimento de folhas e cipós visa atingir concentração máxima de potência visionária, com objetivo de fazer com que o sujeito chegue ao êxtase rapidamente. Momentos de importância terapêutica, nos quais lhe é possível localizar a origem de traumas e infortúnios, e que fazem com que pacientes tomem decisões sobre o rumo e o sentido de suas vidas. $\mathrm{O}$ uso controlado e ritualizado da beberagem, de acordo com os terapeutas da Takiwasi, não provoca dependência, já que, no decorrer do tratamento, os sujeitos tendem a consumir doses menores do enteógeno, além do fato de que eles não sentem compulsão pela ausência da substância, ao saírem recuperados do Centro.

\section{Considerações Pontuais}

Buscamos neste artigo elucidar brevemente o papel conferido à ayahuasca $\mathrm{e}$ outras plantas de poder para algumas tradições indígenas e vegetalistas ameríndias, destacando, acima de tudo, os processos envoltos dos fenômenos da saúde, da doença e da cura imersos em peculiares perspectivas xamânicas inerentes aos encadeamentos físicos e metafísicos, que circundam as medicinas da floresta, sendo a ayahuasca considerada "la madre de todas las plantas". Ressaltamos sua relevância cosmológica dentre povos tradicionais e caboclos sem esquecer-nos de mencionar outras releituras culturais destes saberes para o fomento de modelos terapêuticos, que têm como base os preceitos anímicos das "medicinas ameríndias".

"Medicinas ancestrais" respaldadas na união de vegetais de poder condutores de ações, perspectivas, identidades e mundos em fluxo perpétuo, onde vivos e não-vivos interagem no plano da "consciência cósmica". "Medicinas transcendentais", pois localizam a origem de moléstias e distúrbios, adentrando noutros estados de consciência, estando os corpos, e as sociedades, figurados como reflexos de ordens e desordens no universo, inclusive, elementos concatenados aos mitos e aos ritos indutores de proteção e conduta através de conhecimentos logrados nas esferas metafísicas em conexões com a materialidade. 
"Medicinas paramédicas", quando rutiladas pela magia de Encantados e outros agentes extra-humanos indutores de recobro ou perda da saúde, cuja eficácia subordina-se ao poder do xamã de barganhar com as "forças ocultas", no intento de restaurar e manter o "equilíbrio cósmico", cuja ausência se manifesta em infortúnios individuais e coletivos. "Medicinas pedagógicas", pois, de fato, ensinam aos humanos os mistérios das perspectivas transcendentes a partir das égides imagéticas e visionárias típicas das experiências enteogênicas. Enfim, " $m e$ dicinas agregadoras", uma vez sua persistência na contemporaneidade, apesar dos conflitos e contatos interculturais, a dialogar com outros saberes do Ocidente, no intento de tratar certas patologias que afetam o mundo moderno.

Recebido em 22 de agosto de 2018.

Aprovado em 21 de abril de 2019.

\section{Referências}

ALMEIDA, Mauro. A ayahuasca e seus usos. In: LABATE, Beatriz Caiuby; ARAÚJO, Wladimyr Sena (org.). O uso ritual da ayahuasca. Campinas: Mercado das Letras, 2002, p.15-19.

ANDRADE, Afrânio Patrocínio. O fenômeno do chá e a religiosidade cabocla: Um estudo centrado na União do Vegetal. Dissertação de Mestrado, Ciências da Religião, Instituto Metodista de Ensino Superior, 1995.

ARHEM, Kaj. Makuna social organization: a study in descent, aliance, and the formation of corporete groups in the North-Western Amazon. Estocolmo: Almqvist \& Wiksell, 1981.

BELAÚNDE, Elvira. Gender, commensality and community among the Airo-Pai of West Amazonia (Secoya, Western-Tukanoan Speaking). Tese de Doutorado, Antropologia, Universidade de Londres, 1992.

CHIAPPE, Mario; LEMLIJ, Moisés; MILLONES, Luis. Alucinogenos y Shamanismo en el Peru Contemporaneo. Lima, El Viney, 1985.

CLASTRES, Pierre. Arqueologia da violência: Ensaios de antropologia política. São Paulo, Brasiliense, 1980.

DOBKIN DE RIOS, Marlene. Visionary Vine: Hallucinogenic Healing in the Peruvian Amazon. Prospect Heights. Long Grove, Waveland, 1972.

DOBKIN DE RIOS, Marlene. Curing with Ayahuasca in an urban slum. In: HARNER, Michael (org.). Hallucinogens and Shamanism. Oxford: Universidade de Oxford, 1973, p.67-85.

ESCOBAR, José Arturo Costa. Ayauasca e Saúde: Efeitos de uma bebida sacramental psicoativa na saúde mental de religiosos ayahuasqueiros. Tese de Doutorado, Psicologia Cognitiva, Universidade Federal de Pernambuco, 2012.

GOW, Peter. Of mixed blood. Oxford, Clarendon, 1991.

GOW, Peter. River People: Shamanism and History in Western Amazonia. In: THOMAS, Nicholas; HUMPHREY, Caroline (org.) Shamanism, History and the State. Ann Harbor: Universidade de Michigan, 1996, p.90-113. 
HOFMANN, Albert; WASSON, Gordon Robert; RUCK, Carl. El camino a Eleusis: Una solución al enigma de los misterios. México, Fondo de Cultura Económica, 1980.

KEIFENHEIM, Bárbara. Nixi pae como participação sensível no princípio de transformação da criação primordial entre os índios Kaxinawá no leste do Peru. In: LABATE, Beatriz Caiuby; ARAÚJO, Wladimyr Sena (org.). O uso ritual da ayahuasca. Campinas: Mercado das Letras, 2002, p.97-128.

LABATE, Beatriz Caiuby. A reinvenção do uso da ayahuasca nos centros urbanos. Campinas, Mercado das Letras, 2004.

LABATE, Beatriz Caiuby. Ayahuasca Mamancuna merci beaucoup: Internacionalização e diversificação do vegetalismo ayahuasqueiro peruano. Tese de Doutorado, Antropologia, Universidade Estadual de Campinas, 2011.

LABATE, Beatriz Caiuby; SANTOS, Rafael Guimarães; ANDERSON, Brian; MERCANTE, Marcelo Simão; BARBOSA, Paulo César Ribeiro. Considerações sobre o tratamento da dependência por meio da ayahuasca. NEIP [Online], 2009. Disponível em: https://bit.ly/2LzjZX9 Data de acesso: 20/04/2019.

LAGROU, Els Maria. Uma etnografia da cultura Kashinawa, entre a cobra e o Inca. Dissertação de Mestrado, Antropologia, Universidade Federal de Santa Catarina, 1991.

LAGROU, Els Maria. Caminhos, Duplos e Corpos. Uma abordagem perspectivista da identidade e alteridade entre os Kaxinawá. Tese de Doutorado, Antropologia, Universidade de São Paulo, 1998.

LANGDON, Esther Jean. Representações de doença e itinerário terapêutico dos Siona da Amazônia colombiana. In: SANTOS, Ricardo Ventura; COIMBRA JR., Carlos Eduardo (org.). Saúde e povos indígenas. Rio de Janeiro: Editora da Fiocruz, 1994, p.115-141.

LANGDON, Esther Jean. A tradição narrativa e aprendizagem com yagé (ayahuasca) entre os índios Siona da Colômbia. In: LABATE, Beatriz Caiuby; ARAÚJO, Wladimyr Sena (org.). O uso ritual da ayahuasca. Campinas: Mercado das Letras, 2002, p.69-93.

LÉVI-STRAUSS, Claude. La pensée sauvage. Paris, Plon-Julliard, 1962.

LIRA, Wagner Lins. Os trajetos do êxtase dissidente no fluxo cognitivo entre homens, folhas, encantos e cipós: Uma etnografia ayahuasqueira nordestina. Dissertação de Mestrado, Antropologia, Universidade Federal de Pernambuco, 2009.

LIRA, Wagner Lins. Daqui nós tira um ouro de chá: Umbanda, Santo Daime e xamanismo popular no tratamento religioso de patologias físicas, mentais e espirituais. $O$ caso de um terreiro alagoano. Tese de Doutorado, Antropologia, Universidade Federal de Pernambuco, 2016.

LUNA, Luiz Eduardo. Vegetalismo: shamanism among the mestizo population of the Peruvian Amazon. Tese de Doutorado, Antropologia, Universidade de Estocolmo, 1986.

LUNA, Luiz Eduardo. Xamanismo amazônico: Ayahuasca, antropomorfismo e mundo natural. In: LABATE, Beatriz Caiuby; ARAÚJO, Wladimyr Sena (org.). $O$ uso ritual da ayahuasca. Campinas: Mercado das Letras, 2002, p.181-200. 
LUZ, Pedro. O uso ameríndio do caapi. In: LABATE, Beatriz Caiuby; ARAÚJO, Wladimyr Sena (org.). O uso ritual da ayahuasca. Campinas: Mercado das Letras, 2002, p.37-68.

MABIT, Jean Jacques; CAMPOS, José; ARCE, Julio. Consideraciones acerca del brebaje ayahuasca y perspectivas terapéuticas. Revista de Neuro-Psiquiatría. Lima, Universidade Peruana Cayetano, v.55, n.02, 1992, p.01-13.

MABIT, Jean Jacques. El saber médico-tradicional y la drogadicción. El Filosofo Callejero. Santiago de Chile, n.07, 1995, p.23-39.

MABIT, Jean Jacques. Produção visionária da ayahuasca no contexto dos curandeiros da Alta Amazônia peruana. In: LABATE, Beatriz Caiuby; ARAÚJO, Wladimyr Sena (org.). O uso ritual da ayahuasca. Campinas: Mercado das Letras, 2002, p.147-180.

MACRAE, Edward. Guiado pela Lua: Xamanismo e uso ritual da ayahuasca no culto do Santo Daime. São Paulo, Brasiliense, 1992.

MENDES, Margarete Hitaka. Etnografia preliminar dos Ashaninka da Amazônia brasileira. Dissertação de Mestrado, Antropologia, Universidade Estadual de Campinas, 1991.

MCKENNA, Dennis John. Ayahuasca and human destiny. Journal of Psychoactive Drugs. Londres, Taylor \& Francis, v.37, 2005, p. 231-234.

MERCANTE, Marcelo Simão. Dependência, recuperação e o tratamento através da ayahuasca: Definições e indefinições. Revista Saúde \& Transformação [Online]. Florianópolis, v.04, n.02, 2013, p.126-138. Disponível em: https://bit.ly/2MrRz1m Data de acesso: 20/04/2019.

MOURE, Walter Gustavo. Saudades da Cura: Estudo exploratório de terapêuticas de tradição indígena na Amazônia peruana. Tese de Doutorado, Psicologia, Universidade de São Paulo, 2005.

NARANJO, Plutarco. Ayahuasca: Etnomedicina y Mitología. Quitos, Libri Mundi, 1983.

OLIVEIRA, Alice Haibara. Já me Transformei: Modos de Circulação e transformação de pessoas e saberes entre os Huni Kuin (Kaxinawá). Dissertação de Mestrado, Antropologia, Universidade de São Paulo, 2016.

OTT, Jonathan. Ayahuasca analogues: Pangean Entheogens. Washington, Natural Products, 1994.

RICCIARDI, Gabriela Santos. Takiwasi: O uso da ayahuasca no tratamento da adicção em uma comunidade terapêutica. Tese de Doutorado, Sociologia, Universidade Federal da Bahia, 2013.

SAEZ, Oscar Calávia. Introdução. In: LABATE, Beatriz Caiuby; ROSE, Isabel Santana; SANTOS, Rafael Guimarães (Org.). Religiões ayahuasqueiras: um balanço bibliográfico. Campinas: Mercado das Letras, 2008, p.15-21.

SCHULTES, Richard Evans; HOFFMANN, Albert. Plants of the Gods: Their sacred, healing, and hallucinogenic powers. Rochester, Vermont Healing Arts, 1992.

SISKIND, Janet. To hunt in the morning. Oxford, Universidade de Oxford, 1973. 
TOWSLEY, Graham Elliott. Ideas of order and patterns of change in Yaminahua society. Tese de Doutorado, Antropologia, Universidade de Cambridge, 1988.

VIVEIROS DE CASTRO, Eduardo. A Fabricação do Corpo na Sociedade Xinguana. Boletim do Museu Nacional. Rio de Janeiro, Editora do Museu Nacional, 1979, n. 32, p.40-49.

VIVEIROS DE CASTRO, Eduardo. From the Enemy's Point of View: Humanity and Divinity in an Amazonian Society. Chicago, Universidade de Chicago, 1992. VIVEIROS DE CASTRO, Eduardo. Os pronomes cosmológicos e o perspectivismo ameríndio. MANA [Online], Rio de Janeiro, 1996, v. 02, n. 02, p.115-144. Disponível em: https://bit.ly/2dVusuR Data de acesso: 20/04/2019.

WEIS, Gerald. The cosmology of the Campa Indians of Eastern Peru and Brazil. Tese de Doutorado, Antropologia, Universidade de Michigan, 1969.

WRIGHT, Robin. Profetas do Pariká e Caapi. In: LABATE, Beatriz Caiuby; GOULART, Sandra Lúcia (org.). O Uso Ritual de Plantas de Poder. Campinas: Mercado das Letras, 2005, p.83-115. 


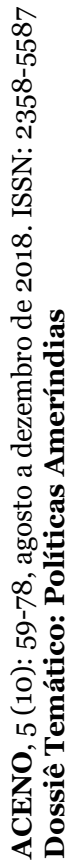

